\title{
Implementation of RCM (Retail Classification Methodology) concept in the distribution system
}

Teaching assistant Ioana Barin - Olariu, University “Vasile Alecsandri” of Bacau

\begin{abstract}
RCM is a methodology through which are described the details of identification and clustering (classification) the outlets, and the customers who visit them. Classification is based on various criteria, which concern both the seller and the buyer. The information resulted from classification makes possible the clustering of different locations which help improve planning and resource allocation, organize the activities and evaluation decisions. This article's purpose is to provide clear information as regards: outletsr classification methodology, the importance of implementation, basic information vs. value-added information, data accuracy and maintainance of information The role of this methodology is to provide clear methods for classification and grouping the locations, based on the identification of clients and retailers.values/ similar needs.
\end{abstract}

\section{Keywords}

Retailers classification, basic information, value-added information, implementation system.

\section{What is the retailers classification methodology (RCM)}

\subsection{The present situation}

Romania currently uses a classification system (RCS) on which were added elements of methodology (RCM). RCS (Retail Classification System) only describes how to collect information, while RCM (Retail classification methodology) also describe how the collected information can be used to improve business performance. In the past, RCS was regarded as a data collection activity and possibly as an implementation system. RCM focuses on using information and ensuring alignment with strategy and plans, making possible these two things. The focus is on optimizing the data to maximize performance at the situation in which the information was collected just in case that will ever be used.

\subsection{The advantages of using the classification}

Once complete the classification of outlets, the benefits are:

- Consumer needs are better identified and satisfied;

- $\quad$ Activities which are to implement could be better planned and designed;

- $\quad$ Efficient allocation of resources and investments;

- People trained for each type of channel (petrol stations, hypermarkets, wholesale, etc.) that would offer to the tradesman competent advice;

- $\quad$ The representative becomes specialized on channel that operates.

\subsection{The importance of implementing RCM}

The classification becomes possible with collecting a minimal amount of information about outlets, and makes it possible to prioritize and ensure that:

- $\quad$ Resources are allocated to outlets that efficiently count;

- $\quad$ The activities are aligned and integrated between brand team and sales force. 
An essential aspect of RCM is that it makes possible the alignment within the organization, by providing a common basis of locations wich both marketing team and sales force work with. Additionally, it ensures a common understanding of some key elements (authority, volume, quality, channel / segment).

It is needed to decide whether held information is out of date, containing relevant details and whether the approach to classification is still in line with strategic and operational plans. Even though different methodologies and new processes were introduced, the need of suitable information on retail to support core business processes (trade coverage planning, territory management, activities prioritizing, etc.) always existed.

However, RCM is focused on optimizing the available information and is useful regardless of what data or systems exist.

A key difference is that the RCM was designed to provide a high degree of flexibility. This has great importance in adapting to local needs, but at the same time it offers a level of global consistency in terms of certain key issues such as channels definition, volume classification, etc. Flexibility also refers to the option to collect over time additional information from the outlets, and then be added into the database without creating disturbances.

\section{Basic information}

RCM offers two levels of data collection. The first step involves providing information that is considered essential / basic and to be collected from as many locations:

- $\quad$ Customer data (static);

- $\quad$ Required basic classifications data.

Basic information is used for:

- Outlets classification;

- Fundamental processes of marketing.

The real value of RCM comes from the efficient interpretation of collected data but also of how other processes influence. The RCM implementation planning must take into account the existing needs and how information in addressing these needs will be used.

Basic information is used in making key decisions on resource allocation:

- What locations will be covered?

- Who will cover these outlets?

- What activities will be implemented and in what locations? What are the main locations for investment?

- What brand is present and in what location?

- What brand activities will be implemented and in what locations?

The answers to these questions underpin the elaboration of strategic and operational plan.

There are several options to collect information:

- $\quad$ TMR (Trade Marketing Representative);

- $\quad$ DR (Distribution Representative);

- $\quad$ MR (Merchandising Representative);

- External staff: research agencies.

Considering the simplistic nature of basic information, they can be collected from any of the above staff. However, information with higher value added must be collected by the companies staff, preferably TMR. Much of the basic data (at least those on the dealer) may already be available in the system or may be obtained from:

- Public institutions: Chamber of Commerce, etc.;

- $\quad$ Other companies: purchase database; 
- $\quad$ Research agencies: Nielsen may have a list of outlets.

Basic information are:

\subsection{Information about the customer}

It refers to basic information about the outlet (eg name, address, phone, etc.). This information is used to establish the territories to be visited addition who visit them.

\subsection{Information for basic classification}

It refers to data required for outlets classification. It includes 2 sets of data:

- $\quad$ Elementary classification (minimal information);

- Additional information.

The information required to be collected is related to volume, channel, type of outlet, authority, consumers age, etc. It is possible to collect additional information to facilitate the planning, classification process.

\subsection{Channel and subchannel}

Defining different types of channels is based on consumer behavior and on the methods by which it can interact with them. In current terms of market dynamics, categories profile constantly change, the boundary between different types of channels becoming thinner. Ex: Convenience - Gas Stations which have inside cafe + a small outlet also. Under this interpenetration circumstances, each place with separate management is separately classified

\subsection{Authority}

Another important information refers to the power of decision of the location person of contact on distribution, merchandising, price and order. Authority intervenes in the establishment of:

- Who will visit the outlet? Eg if decisions are taken in the outlet, it can be send a TMR to positively influence the decisions, over an account where decisions are taken centrally

- What will the frequency of visiting? Eg: how often to visit an outlet on which decisions can't be influenced.

- What types of activities need to be made? Eg: if the person can decide on the order, a visit of a DR is required to take it.

Information about the authority is included in:

- Objectives planning;

- Developing marketing activities that are appropriate for each type of authority;

- Appropriate reports.

\subsection{Information about outlets location}

Location: This information provides clues about area's features where the location is situated.

Proximity: Represents those locations that are situated in residential areas, whose clients are mostly the same. The business potential comes from the fact that the seller knows the majority of customers, knows their preferences and his recommendation may influence a lot the buying decision.

\subsection{Additional information that are necessary to the classification}

Depending on the features of a market, it can collect other information, if they help in classification process. All such information, in each market, will provide additional data that will result in advanced planning, implementation and evaluation.

Examples include:

- Contracts;

- Supply sources; it is recommended that this type of information to be collected, because it will facilitate the analysis of product flow in the secondary distribution chain;

- $\quad$ The economic environment in which the outlet is located. 


\section{Value-added information}

After the basic information is collected, a basic classification is done, which indicates the priority locations in which it is useful to collect value-added information.

Types of value-added information:

- $\quad$ Data about the consumer;

- Data about segments of consumers;

- Data about consumer behavior;

- Criteria on merchant;

- Data about communication;

- Data about employees;

- $\quad$ Other criteria.

\subsection{Data about the consumer}

It is information about the consumers, which helps planning / prioritization, it may include:

- Share of women/men;

- Income and / or education.

\subsection{Data about segments of consumers}

It is information about the segments of consumers who visit a location; can help identify and prioritize:

- $\quad$ Products like: clothes, drinks, accessories, etc..;

- Social group who visit the location.

\subsection{Data about consumer behavior}

The decision on which such information will be collected are taken centrally, based on consumers research. If locally there is some information about consumer behavior that bring aid in planning, implementing and evaluation, they will be mentioned.

\subsection{Merchant criteria}

It is possible that additional information about the merchant to prove useful, especially for Horeca, where staff can be used as a "brand ambassador".

Information can include:

- Age;

- Domain experience;

- $\quad$ The ability to influence the.consumers

\subsection{Data about the communication}

A key example of this category is the percentage of shelves exposure - "Facing share", which offers the possibility of measure the exposure rate of outlet. Improving of this indicator may be a key aspect of operational plans.

\subsection{Data about employees}

This data may be collected, especially if there are plans to use the employees as "brand ambassadors" or in other programs in which they are involved. It may collect information about:

- $\quad$ Number of employees and the staff turnover;

- Motivation and ability to influence;

- $\quad$ Attitude towards the FMCG field.

\subsection{Other criteria}

In large part, it refers to HoReCa, because of its different specificity from retail, so is required typical data collection of this channel, taking into account the recommendations of the research team:

- Existing contracts;

- $\quad$ The kind of music;

- The prices;

- Various restrictions. 


\subsection{Additional information to those used in the classification}

As part of the collection of data, it may be decided raising additional information which will not be used for classification:

- $\quad$ Dealer contact - eg: email, name, favourite visit day.;

- $\quad$ Merchandising data - POP / POS materials existing in outlets;

- Contract data - details of existing contracts;

- $\quad$ Financial data - eg: credit period, credit limit, etc.;

- Competition data.

Collecting such data is a component of the implementation process, especially if this information was not available previously.

RCM should be treated as a method to obtain an approximation of outlets. Although the accuracy of collected data is a priority, should not be lost of sight the cost and complexity resulting from the effort of errors minimizing.

\section{Data maintenance}

Once collected the information, it should be updated continuously. It is necessary to set the person responsible for this activity (in principle, the person who visits the outlets).

For the outlets viewed more than one representative, it is necessary to set each area of responsibility. The recommendation is that DR (Distribution Representative) should handle basic and financial information, while TMR (Trade Marketing Representative) should handle the value-added and ratings.

\section{Bibliography}

1. Dwyer, F.R.; Tanner, J.F., (2006), Business Marketing, McGrew-Hill, New-York, 3rd edition

2. Gattorna, J.L., (1999), Managementul logisticii si distributiei, Publishing House Teora, Bucuresti

3. Peter, J.P.; Olson, J.C., (2008), Consumer Behavior and Marketing Strategy, McGrewHill, New-York, 8th edition

4. Weitz, B.A.; Castleberry, S.B., (2007), Selling - building partnerships, McGrew-Hill, New-York, 6th edition

5. www.magazinulprogresiv.ro 